\title{
Medium-priority Tuberculosis Subject
}

National Cancer Institute

\section{Source}

National Cancer Institute. Medium-priority Tuberculosis Subject. NCI Thesaurus. Code C102665.

An individual that has tested negative for pulmonary, laryngeal, or pleural tuberculosis but has had a non-cavitary chest $\mathrm{x}$-ray that is consistent with tuberculosis. 